\title{
A NOVEL APPROACH ON POWER ELECTRONICS CONVERTER BASED ADAPTER
}

\author{
Jotirmoy Samanta \\ Student, Department of Renewable Energy and Energy Management \\ NIT Arunachal Pradesh, Yupia, India
}

\begin{abstract}
Hybrid Portable Universal Adapter is very efficient and new technology which has capable of taking $\mathrm{DC}$ and $\mathrm{AC}$ input both and can provide constant DC output. This paper presents renewable energy like Solar panels as DC source and normal AC (230V RMS) source. It has controlled circuit incorporated in it to step down AC voltage without using transformer. This model can give constant DC output of $5 \mathrm{v}$. This circuit has parallel converter circuit which converts AC to DC and DC to DC as well. This adapter can be carried easily and we can use it to charge our mobile phones or any power bank.
\end{abstract}

Keywords - AC- Alternate current, DC- Direct Current, RMS- Root Mean Square, TRIAC-Triode for Alternating Current, PWM- Pulse Width Modulation, PI- Proportional Integral.

\section{INTRODUCTION}

Mobile is very important technology for every person presently. So powering it continuously and efficiently is very essential. People use to carry charger with them but power supply may not be available all the time at every place. So we can make use of renewable energy like solar panels to give supply to our mobile. The use of solar power system for generation of electricity nowadays it is widely used [1]. As the result of the increasing cost and environmental pollution concerns of the power generation from fossil fuels, nowadays the power generation is moved towards the renewable energy sources. Users always prefer mobile phones with advanced technology. However, charging our phone is a common problem during travelling because every time power sources are not available everywhere. Wind turbine can also be used as renewable energy source [2]. Then for that we need generator and propeller and the system will be bigger and it will be difficult to carry from one place to another. Peltier tiles can also be used as renewable energy source to convert heat energy to electrical energy [3]. It is difficult to get both AC and DC source every time and everywhere. Universal charging technique can take both $\mathrm{AC}$ and $\mathrm{DC}$ source. So we can get both options for charging. The mobile is powered from either the main grid or from the solar panel. It depends on the mode of charging selected [6]. The TRIAC conducts when it has been triggered and holds latching current, and shuts down when the current is less than the TRAIC hold current. The TRAIC poplar's reason is that it can be triggered at any time of the sinusoidal voltage and can be kept in conduction state until reaching zero line voltage [7]. So we can use TRIAC for AC power control, it is a power electronics device which controls AC power by triggering it. Transformer makes the system big in size and heavy. From grid we can omit transformer for stepping down the $\mathrm{AC}$ voltage using power electronics components like TRIAC. We can make use of DC-DC Power converters to convert variable de input to stable DC voltage [4]. We can make wireless charger using inductive coupling method [5]. But then there will be no fast charging and lots of components required to make that system and power losses will be there. Rather than renewable energy $9 \mathrm{~V}, 12 \mathrm{~V}$ or $24 \mathrm{~V}$ battery can be used as DC source for this converter.

\section{METHODOLOGY}

Solar panel is used for DC source and there is 230V RMS backup system. If there is sufficient amount of power output from solar panel then DC supply will be encountered from Solar panels or else 230V RMS can be used as backup system. For DC source PI controlled DCDC buck converter is use to convert the variable DC input voltage to constant $\mathrm{DC}$ output. For AC source the voltage is regulated using TRIAC and then bridge rectifier is used to convert AC power to DC power. A common capacitor filter is used at the output to reduce the ripple voltage of the output for both the converter. A switch is implemented for switching to Mode1 when DC supply is available.

\subsection{AC-DC CONVERTER}

230V RMS AC can be provided to the system. TRIAC is use to step down the AC voltage. To rectify DC voltage from AC voltage bridge type rectifier is used and then it is connected to the load through a common filter circuit. This system is a transformer less circuit to convert high level AC voltage to low level AC voltage. Power Converters are very efficient technology in the field of Power electronics, so this whole model is based on power electronics switches. An inductor is there in the output of the AC-DC converter circuit to reduce the ripple from the output. A Resistor and Capacitor control circuit has been used to create the PWM signal for the TRIAC. PWM signal is send to the gate terminal of the TRIAC through a DIAC. 


\subsection{TO DC CONVERTER}

Solar panels can be used to provide DC supply to the circuit. DC-DC Buck converter is incorporated in this adapter circuit. $12 \mathrm{~V}$ to $24 \mathrm{~V}$ DC can be supplied to this adapter by solar panels or by battery or by any other power source. PI controller controls this circuit for constant DC output. A common Capacitor filter is used to minimize the ripple output voltage. MOSFET has been used for switching in this model. PI controller has been tuned with the help of simulation. First set the I value to 0 and then by increasing the $\mathrm{P}$ value the output is set in such a way that it oscillates constantly. Then gradually increasing the I value will make the oscillation less.

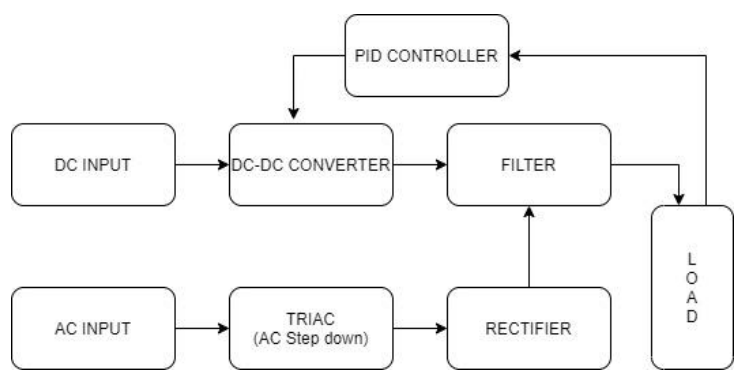

Fig.1. Block Diagram

\section{WORKING MODES}

\subsection{MODE1}

When there is DC input DC Buck converter will be activated and load will be supplied by DC loop through a capacitor filter. PI controller will control the switching of the DC-DC converter, which will give constant DC output voltage as per requirements.

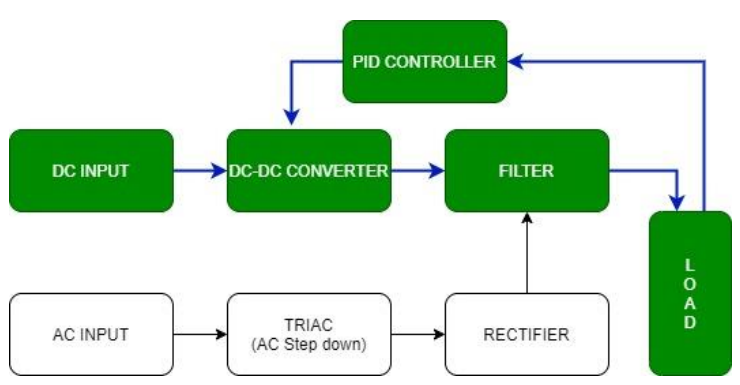

Fig.2. Mode 1 Block Diagram

\subsection{MODE2}

When there is $\mathrm{AC}$ input is available then we can use AC loop and we can supply to the load. Bridge type rectifier is used to convert $\mathrm{AC}$ to $\mathrm{DC}$ and then the output of rectifier is connected to a common Capacitor filter to minimize the ripple of the rectified output.

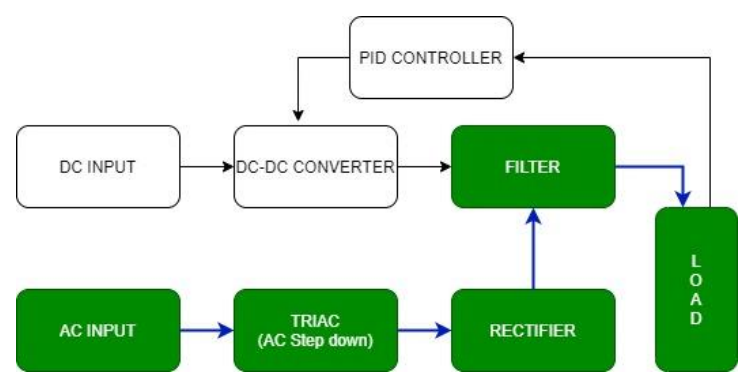

Fig.3. Mode 2 Block Diagram

\section{CALCULATION}

Duty cycle of the DC-DC converter has been calculated using formula $\left(D=V_{\text {out }} / V_{\text {in }}\right)$ (1). Where $\mathrm{D}$ is duty cycle, $V_{\text {out }}$ is output voltage of the model and $V_{\text {in }}$ is input DC voltage of the model. Time period of PWM signal for the MOSFET switch is calculated by formula $\left(T=T_{O N} / D\right)$ (2). Where T is the total time period of the switching PWM signal and $T_{O N}$ is the switching $\mathrm{ON}$ time period. Inductor used in the DC-DC converter is calculated using formula $\left(L_{\min }=D_{\max } * \frac{V_{\text {in } \max }-V_{o}}{\Delta i_{L} p * f_{S w}}\right)$ (3) [13]. Where $L_{\text {min }}$ is minimum inductor to be selected for the converter, $D_{\max }$ is maximum duty cycle, $V_{\text {in max }}$ is maximum input DC voltage, $V_{o}$ is the output voltage of the converter, $\Delta i_{L p p}$ is ripple inductor current and $f_{s w}$ is switching frequency of the converter. Capacitor filter calculation has been done by the formula $\left(C=\frac{I}{2 * f * V_{p p}}\right)$ (4) [9]. Where $\mathrm{C}$ is Capacitor value, $I$ is the output current, $f$ is frequency of the waveform and $V_{p p}$ is ripple output voltage.

\section{Calculation Results:}

\begin{tabular}{|l|l|}
\hline Duty cycle (D) & $41.66 \%$ \\
\hline Time period (T) & $12 \mathrm{mS}$ \\
\hline Switching Frequency & $83 \mathrm{~K} \mathrm{~Hz}$ \\
\hline Inductor (L1) & $476.9 \mathrm{uH}$ \\
\hline Capacitor(C3) & $17.85 \mathrm{mF}$ \\
\hline
\end{tabular}

\section{SIMULATION}

Simulation for the whole system is done in Matlab Simulink. Components parameters are manually calculated by using desire formulas. Calculated components parameters are set to the Simulink model for simulation purpose. For simulation purpose two ideal switches has been used to select in which mode the model should work. In simulation Thyristors are used to make the equivalent circuit of the TRIAC. The output voltage and output current is measured using voltage and current measurement block and the graphs have been executed in scope. As the time period of the PWM signal for MOSFET switch is 12micro seconds, the repeating signal used for PI control is also made 12 micro seconds. Two diodes have been used to make the equivalent circuit of DIAC to provide the PWM signal to the TRIAC. For bridge type rectifier four diodes are used after TRIAC circuit. All simulation results is of 60 
seconds time. $\mathrm{X}$ - axis of every simulation results is of time Fig.6. Output Voltage and Output Current Waveform of in seconds. $\mathrm{Y}-$ axis of output voltages is in Volts and of $12 \mathrm{~V}$ DC Input

output current is in Ampere.

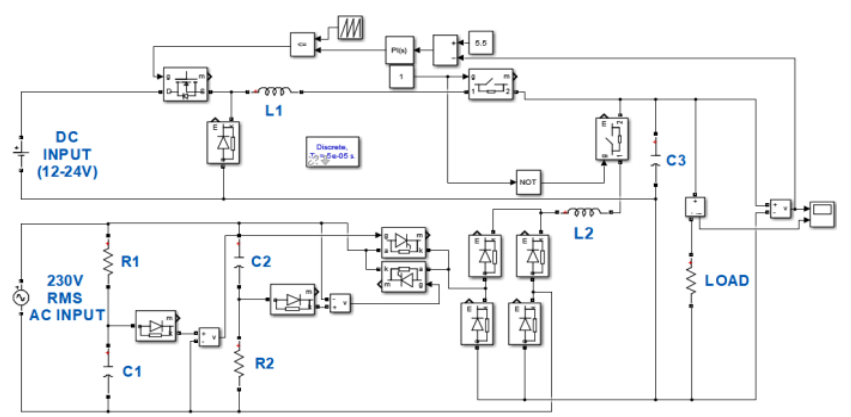

Fig.4. Simulation Diagram

\section{Simulation Values:}

\begin{tabular}{|l|l|}
\hline L1 & $500 \mathrm{uH}$ \\
\hline L2 & $44 \mathrm{mH}$ \\
\hline R1,R2 & $80 \mathrm{~K} \mathrm{Ohm}$ \\
\hline C1,C2 & $12 \mathrm{uF}$ \\
\hline C3 & $30 \mathrm{mF}$ \\
\hline LOAD & $1 \mathrm{Ohm}$ \\
\hline P & 0.05 \\
\hline I & 4 \\
\hline
\end{tabular}

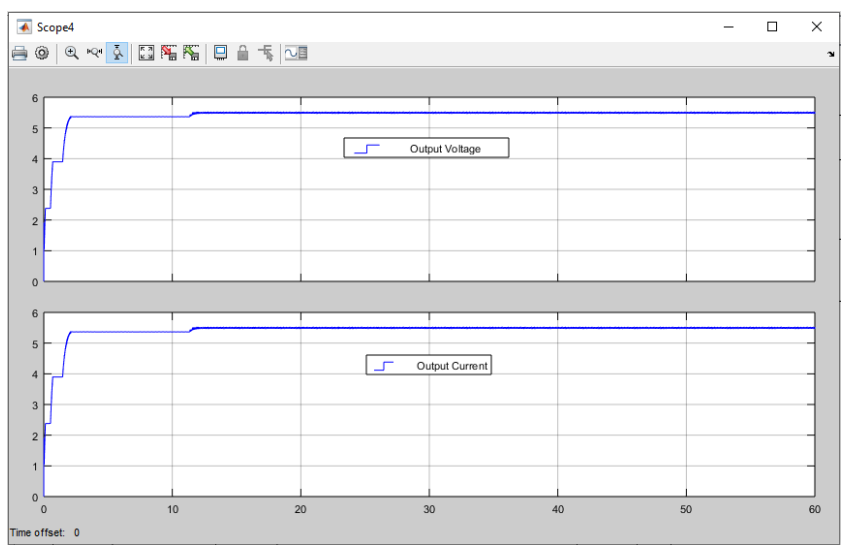

Fig.5. Output Voltage and Output Current Waveform of 9V DC Input

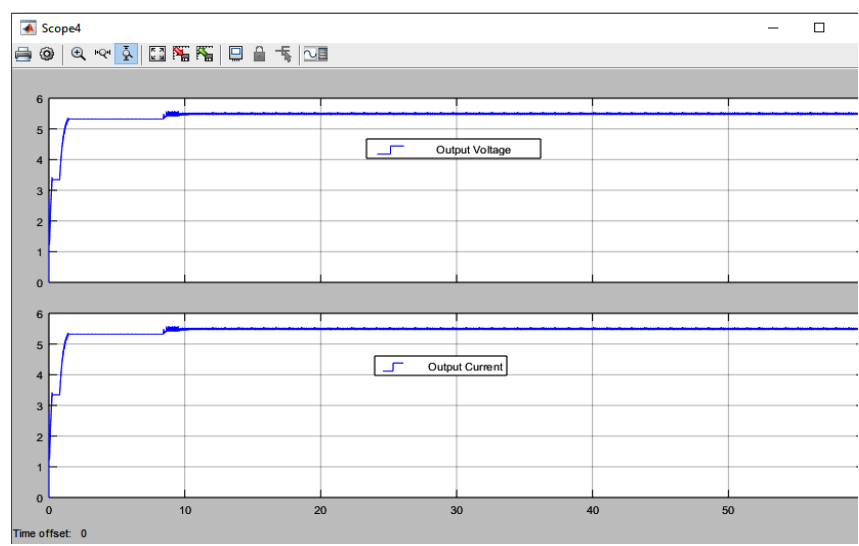

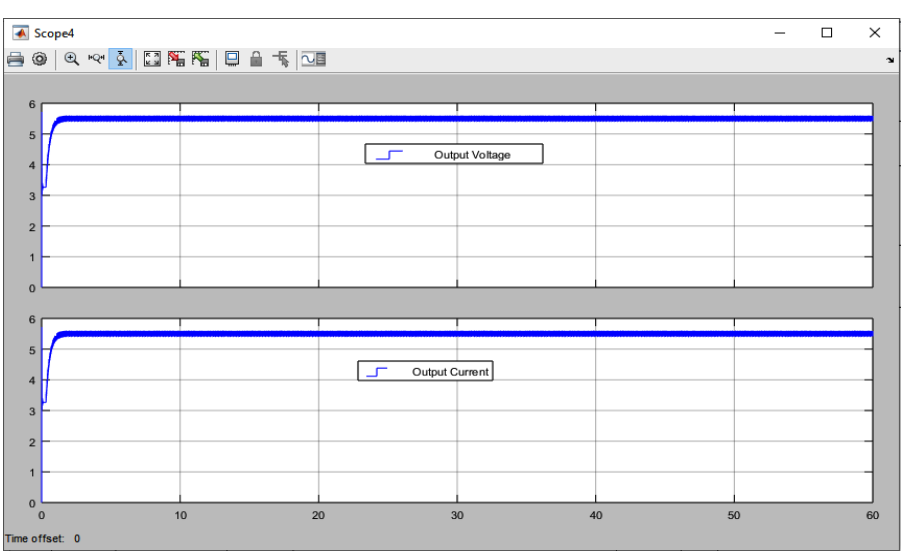

Fig.7. Output Voltage and Output Current Waveform of 24V DC Input

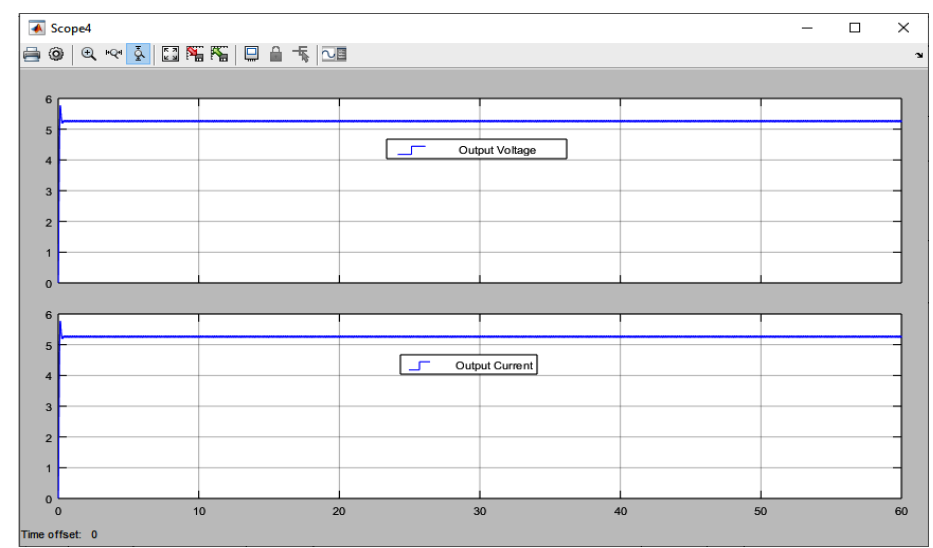

Fig.8. Output Voltage and Current Waveform of $230 \mathrm{~V}$ RMS AC Input

\section{CONCLUSION}

This system can be used for charging mobile and powering $5 \mathrm{~V}$ devices. It is very efficient and can be used for fast charging. It is easy to carry anywhere and can use both AC and DC supply. Rather than solar panel or any other means of renewable source we can also use $12 \mathrm{~V}$ or $24 \mathrm{~V}$ batteries as DC source for this system. Constant 5V DC output has been executed in MATLAB software.

\section{REFERENCES}

[1] Barad Aishwarya, Tungar Shubhangi, Sangle Namita, Bharambe Ketan, Dr. Kadam D.P., (2017) "Solar Panel Based Multi-Mobile Charger with LED Illumination", International Conference on Innovations in information Embedded and Communication Systems (ICIIECS)

[2] Ratnakumar Rajan, Vinushika Panchalogaranjan, Visvakumar Aravinathan, Tharmarajah Thiruvaran, Vinothine Shanmugarajah, (2018) "Low cost portable wind power generation for mobile charging applications", IEEE International Conference on Information and Automation for Sustainability (ICIAfS) 
[3] Kannan Haripriya, Reshme T K, Parthiban Preethy, (2016) “Thermoelectric Charger", Online International Conference on Green Engineering and Technologies (ICGET)

[4] Ting-Lien Wu, Jia-Sheng Hu, (2016) "Dual-Input DCDC power converter for Solar Battery Charger", IEEE 11th Conference on Industrial Electronics and Applications (ICIEA)

[5] M. Fareq, M. Fitra, M. Irwanto, Syafruddin. HS, N. Gomesh, Farrah. S, M. Rozailan, (2014) "Solar Wireless Power Transfer Using Inductive Coupling for Mobile Phone Charger", IEEE 8th International Power Engineering and Optimization Conference (PEOCO2014)

[6] Visal Raveendran, Divya R., Sreya Chandran P. C., Manjula G. Nair (2017) "Smart Level 2 DC Electric Vehicle Charging Station with Improved Grid Stability and Battery Backup", IEEE International Conference on Technological Advancements in Power and Energy ( TAP Energy )

[7] Chih-Wei Lin, Ying-Yu Tzou (2012) "Digital voltage control of boost CRM PFC AC/DC converters with TRIAC Phase Control dimmer", IEEE International Conference on Power System Technology

[8] Phulambrikar S. P., Gupta M. (2014), Design and Analysis of Buck Converter, International Journal of Engineering Research \& Technology (IJERT), (pg-23462350)

[9] https://makingcircuits.com/blog/calculate-filtercapacitor-smoothing-ripple/

[10] Zaw Min Min Htun, Kyaw Zin Latt, Myo Maung Maung. (2019), International Journal of Trend in Scientific Research and Development (IJTSRD), (Pg-2082-2085)

[11] J K Udayalakshmi, S Sheik Mohammed. (2018), Design and Implementation of Solar Powered Mobile Phone Charging Station for Public Places, Proceeding of 2018 IEEE International Conference on Current Trends toward Converging Technologies

DOI: 10.1109/ICCTCT.2018.8551180

[12] https://www.researchgate.net/publication/321137100_T hyristor_Triac and Diac

[13] https://www.powerelectronicsnews.com/the-buckregulator-power-supply-design-tutorial-part-2-1/ 